\title{
PERAN ULAMA SEBAGAI RESOLUSI KONFLIK CAROK DI DESA KALIBOTO KIDUL KECAMATAN JATIROTO LUMAJANG
}

\author{
Abdul Ghofur \\ Fakultas Dakwah dan Komunikasi Islam \\ Institut Agama Islam Syarifuddin Lumajang \\ abdul.ghofuro20382@gmail.com
}

\section{ABSTRACT}

Violence cannot be separated from the role of humans as the perpetrators. One of the many cultural activities owned by Madurese tribe in Kaliboto Kidul, Jatiroto, Lumajang is carok, a deeply rooted culture that has become a tradition. Inspired by A Latief Wiyata's thoughts, the problem that will be raised in this research is how the role of local ulama to resolve such problem. This study employs qualitative research with a descriptive approach. Its orientation is to understand the meaning of the indications and phenomena that occur in Kaliboto Kidul, Jatiroto, Lumajang. In the process of retrieving data, researchers uses observation, interview and documentation techniques. Data analysis techniques used are data reduction, data presentation and conclusion drawing. The results of the study shows that carok in this area is described as an attempt to kill each other which is committed by men using sharp weapons in the form of celurit. The causing issues are self-esteem harassment, inheritance and revenge actions.

Keywords: ulama, carok, and criminal law

\section{PENDAHULUAN}

Ulama erat berhubungannya dengan sesuatu gelar yang menekankan pemuliaan dan pengakuan, yang diberikan masyarakat secara sukarela kepada orang muslim tertentu sebagai pimpinan agama atau tokoh masyarakat. Dikalangan masyarakat Islam tradisional Jawa, Ulama merupakan tokoh keagamaan kharismatik, berwibawa dan alim yang bisa di jadikan panutan. ${ }^{1}$

Seorang Ulama memiliki kelebihan ilmu dan amal yang tidak dimiliki lazimnya orang dan kebanyakan memiliki lembaga pendidikan yang dipimpinnya. ${ }^{2}$ Peran sosial Ulama yang begitu besar dalam menghalangi orang yang hendak melakukan 
carok.3Pihak yang akan melakukan Carok biasanya lebih dulu sowan (bertamu atau mohon restu) dan minta nasehat kepada Ulama, bila tidak memberikan restunya, maka tidak akan melanjutkan rencana carok. 4

Istilah carok sebenarnya merupakan suatu istilah terhadap kekerasan yang dilakukan oleh masyarakat Madura pada umumnya, namun hal ini juga terjadi pada masyarakat Lumajang yang notabene berbudaya Madura secara mayoritas kendati bukan Madura secara geografi. Masyarakat Lumajang dikenal dengan masyarakat pandalungan ${ }^{5}$ yang mewarisi perilaku orang Madura secara utuh yang terlihat dalam penggunaan clurit. Hal-hal yang membedakan dalam penggunaan celurit karena celurit merupakan alat yang digunakan ketika melakukan carok. ${ }^{6}$ Menurut A. Latief Wiyata, carok adalah pengejawantahan nilai-nilai sosial budaya yang berkembang selama ini.

Bagi masyarakat berbudaya Madura ungkapan; "mangok pote tolang etembang poteya mata", (lebih baik putih tulang dari pada putih mata) yang berarti "lebih baik mati dari pada menanggung rasa malu" dan ungkapan yang lebih tegas; "thambana todus, mate", atau (obatnya malu adalah mati) adalah merupakan prinsip dalam melakukan carok yang dilakukan untuk membela atau mempertahankan harga diri dan kehormatan. Oleh karena itu, tindakan carok oleh sebagian masyarakat dibenarkan secara kultural juga mendapat persetujuan sosial.

Carok merupakan salah satu alternatif penyelesaian sengketa pada masyarakat berbudaya Madura dengan menggunakan jalur kekerasan. ${ }^{7}$ Cara seperti ini biasanya

${ }^{3}$ Carok adalah suatu tindakan atau upaya pembunuhan menggunakan senjata tajam -pada umumnya clurit yang dilakukan oleh laki-laki terhadap laki-laki lain yang telah dianggap telah melakukan pelecehan terhadap harga diri, terutama berkaitan dengan masalah kehormatan diri, istri dan agama sehingga membuat todus (malu). Berdasarkan pengertian ini, paling tidak terdapat lima unsur yang tercakup dalam pengertain carok, yaitu tindakan atau upaya pembunuhan antar laki-laki; pelecehan harga diri, terutama berkaitan dengan kehormatan diri, perempuan dan agama; perasaan malu (todus); adanya dorongan, dukungan, serta persetujuan sosial; perasaan puas dan bangga bagi pemenangnya. Wiyata, Carok..., h. 184.

4 Ibnu Qayyim Ismail, Kiai Jawa dan Peranannya di Masa Kolonial, Jakarta: Gema Insani Press, 1997, h. 60.

${ }_{5}^{5}$ Masyarakatpandalungan adalah masyarakat hibrida akibat terjadinya percampuran dua budaya dominan yaitu budaya Jawa dan budaya Madura. Pada umumnya masyarakat pandalungan bertempat tinggal di daerah pedesaan mulai dari pesisir pantai hingga pegunungan, lihat: Ayu Sutarto, "Sekilas tentang Masyarakat Pandalungan," Makalah disampaikan pada acara pembekalan Jelajah Budaya 2006 yang diselenggarakan oleh Balai Kajian Sejarah dan Nilai Tradisional Yogyakarta, tanggal 7-10 Agustus 2006. Lihat Pula: Subahri, Bambang. Pesan simbolik tradisi sandingan pada masyarakat pandalungandi desa Jenggrong kecamatan Ranuyoso kabupaten Lumajang. Dakwatuna Jurnal Vol. 4 No. 2 Agustus 2018.

${ }^{6}$ Ibnu Hajar, Carok, Sarkasme Orang Madura, http:// www.kaskus.us/ showthread php, 04 Januari 2019.

7 Dikalangan masyarakat Madura terdapat satu ungkapan yang berbunyi "Otang pate, majar pate. Otang nyaba majar nyaba ( hutang mati, dibayar dengan mati. Hutang nyawa dibayar dengan nyawa ) jika seseorang membunuh berarti dia mempunyai “utang kematian" sehingga dia harus membayarnya dengan kematian pula. 
tidak menyelesaikan masalah tapi dapat memunculkan sengketa yang lain. Menjelang Carok berlangsung, kedua belah pihak pelaku Carok biasanya melakukan ritual-ritual tertentu dirumahnya seperti: selamatan $^{8}$ dan pembekalan agama berupa pengajian dan biasanya dipimpin oleh Ulama atau tokoh masyarakat. Oleh keluarganya, bahkan keluarga pelaku Carok sudah mempersiapkan dan mengikhlaskan pelaku untuk terbunuh. ${ }^{9}$

Berdasarkan latar belakang di atas maka peneliti tertarik mengungkap fenomena carok. Dalam masalah ini, perlu diteliti karena penyelesaian dengan cara kekerasan (carok) yang terjadi di Desa Kaliboto Kidul sangat bertentangan dengan hukum positif maupun hukum Islam disamping itu juga mendorong penyusun untuk mengkaji gejala-gejala yang terjadi ditengah-tengah masyarakat di Desa Kaliboto Kidul Kecamatan Jatiroto Kabupaten Lumajang, sehingga hasil-hasil tersebut seterusnya dapat dijadikan bahan pertimbangan dan rujukan dalam karya ilmiah.

Berangkat dari latar belakang permasalahan yang menyangkut tentang masyarakat Kaliboto Kidul, yang mana mengenai masalah tentangperanan Ulama terhadap Carok, maka penyusun merumuskanpermasalahan sebagai berikut:Bagaimana peranan Ulama dan Metode apa yang digunakan dalammenyelesaikan dinamikacarok di Desa Kaliboto Kidul?

Penelitian ini dilakukan dengan tujuan sebagai berikut: untuk mengetahui peranan Ulama dan Metode apa yang digunakan dalam menyelesaikan dinamikacarok di Desa Kaliboto Kidul.

Hasil penelitian diharapkan dapat memberikan manfaat berbagai pihakyang berkompeten, baik secara teoritis maupun praktis.

1. Bagi kehidupan masyarakat, penelitian ini diharapkan mampumemberikan gambaran kepada masyarakat tentang budaya suku Madurayang dapat dikatakan

8 Ritual slametanbiasanya terdiri dari nasi kuning dan apem (sejenis kue) yang dimakan secara bersama-sama segera setelah dipimpin doa oleh seseorang kiai langgar. Doa biasanya diawali dengan puji-pujian (shalawat) kepada Nabi Muhammad SAW dan para sahabat, namun kemudian sang pemimpin doa juga memanjatkan doa tersebut kepada para leluhur dan danyang desa. Ritual keagamaan ini biasanya juga diawali dengan do'a, dalam: Robert W. Hefner, Islam Pasar Keadilan: Artikulasi Lokal, Kapitalisme dan Demokrasi. (Yogyakarta: LKiS. 2000), h. 107. Lihat juga: Zaini Muchtarom, Islam di Jawa dalam Perspektif Santri dan Abangan. (Jakarta: Salemba Diniyah, 2002), h. 56-57. Lihat pula: Lihat Pula: Subahri, Bambang. Pesan simbolik tradisi sandingan pada masyarakat pandalungandi desa Jenggrong kecamatan Ranuyoso kabupaten Lumajang. Dakwatuna Jurnal Vol. 4 No. 2 Agustus 2018.

9 Wiyata, Carok..., h. 199. 
ekstrim, serta gambaran sikap moral atas budayatersebut, agar masyarakat dapat menyikapinya secara kritis.

2. Bagi peneliti, penelitian ini diharapkan dapat memberikanperkembangan ilmu pengetahuan. Penelitian ini memaparkan tentangcarok yang diharapkan dapat memberikan kontribusi positif dan dapatmemperkaya khasanah ilmu pengetahuan manusia, khususnya dalambidang hukum.

\section{METODE}

Jenis penelitian ini adalah penelitian lapangan yang didukung dengan pendekatan kualitatif. ${ }^{10}$ Pendekatan yang dilakukan dalam penelitian ini adalah: Pertama, pendekatan yuridis yaitu pendekatan yang dilakukan dengan cara mendeteksi masalah-masalah yang diteliti dengan mendasarkan pada hukum Islam. Kedua, pendekatan normatif yaitu cara mendekati masalah yang diteliti dengan melihat apakah sesuatu itu baik atau tidak berdasarkan norma-norma hukum yang berlaku. Ketiga, pendekatan historis yaitu cara mendekati masalah yang diteliti dengan melihat perkembangan peranan Ulama terhadap budaya carok. ${ }^{11}$

Peneliti hanya difokuskan pada lokasi di Desa Kaliboto Kidul Kecamatan Jatiroto Kabupaten Lumajang yang sering kali terjadi konflik kekerasan (Carok). Adapun sumber data primer atau subjek dalam penelitian ini di antaranya: ${ }^{12} \mathrm{KH}$. Abdul Aziz dan Ustd. Muhammad Yusuf Ya'kub yang merupakan seorang Ulama sekaligus tokoh masyarakat di Desa Kaliboto Kidul.Sedangkan data sekunder diperoleh dari sumber tidak langsung yang biasanya berupa data dokumentasi dan arsip-arsip resmi. ${ }^{13}$ Data tersebut terdiri atas undang-undang KUHP dan bahan kepustakaan berupa kitab Fiqh dan buku-buku penunjang lain yang berkaitan dengan masalah yang diteliti.

Teknik Pengumpulan Data menggunakanMetode Observasi dan Metode Interview (Wawancara). Observasi yang dilakukan dalam penelitian ini adalah untuk mengetahui secara langsung sikap Ulama serta kondisi masyarakat di Desa Kaliboto Kidul dengan dekat. Sedangkan jenis interview menggunakan jenis bebas terpimpin

\footnotetext{
${ }^{10}$ Lexy J. Moloeng, Metode Penelitian Kualitatif, Bandung: Remaja Rosda Karya, 2002, h. 3.

${ }^{11}$ lbid., h. 6.

${ }^{12}$ Sugiyono, Memahami Penelitian Kualitatif, Bandung: Alfabeta, 2005, h. 62.

13 Saifuddin Azwar, Metode Penelitian, Yogyakarta: Pustaka Pelajar, 2005, 36.
} 
yaitu peneliti sebagai pewawancara membawa pedoman yang hanya merupakan garis besar tentang hal-hal yang akan ditanyakan. ${ }^{14}$ Dalam hal ini penyusun mengadakan wawancara langsung terhadap para Ulama, tokoh masyarakat.

Untuk teknik analisis data yang digunakan bersifat eksploratif, deskriptif analitis yaitu menguraikan menggambarkan, memaparkan dan menganalisis tentang realita kehidupan status fenomena masyarakat bersuku Madura yang berkaitan dengan Carok serta peranan Ulamanya. Dengan tetap memperhatikan prinsip validitas, otentitas dan reliabilitas, kemudian dianalisis dengan instrumen analisis induktif dan komparatif.

\section{PEMBAHASAN}

1. Peran Ulama dalam Upaya-Upaya Penyelesaian DinamikaCarok di Desa Kaliboto Kidul

a. Pengertian Ulama

Menurut Kamus Besar Bahasa Indonesia, Ulama adalah orang yang ahli dalam hal atau dalam pengetahuan agama Islam. Kata Ulama berasal dari bahasa Arab, bentuk jamak dari kata "alim". Alim adalah isim fa'il dari kata dasar Ilmu. Jadi alim adalah orang yang berilmu dan Ulama adalah orang-orang yang berilmu.

Ulama عالم yang artinya adalah pemuka agama atau pemimpin agama yang bertugas untuk mengayomi, membina dan membimbing umat Islam baik dalam masalah-masalah agama maupun masalah sehari-hari yang diperlukan baik dari sisi keagamaan maupun sosial kemasyarakatan. Makna sebenarnya dalam bahasa Arab adalah Ilmuwan atau peneliti, kemudian arti Ulama tersebut berubah ketika diserap kedalam bahasa Indonesia, yang maknanya adalah sebagai orang yang ahli dalam ilmu agama Islam. ${ }^{15}$

Pengertian Ulama secara harfiah adalah orang-orang yang memiliki Ilmu. Dari pengertian secara harfiah dapat disimpulkan bahwa Ulama adalah:

1) Orang muslim yang menguasai ilmu agama Islam. 
2) Muslim yang memahami syariat Islam secara menyeluruh (kaaffah) sebagaimana terangkum Al-Quran dan As-Sunnah.

3) Menjadi teladan umat Islam dalam memahami serta mengamalkan. ${ }^{16}$

Ulama merupakan faktor pemersatu dalam tatanan sosial masyarakat. Ulama juga memberi nasehat dan bimbingan kepadawarga desa dalam urusan ekonomi dan kepentingan bisnis. Tidakmengherankan bila dalam konteks ini kedudukan Ulama begitupenting dalam masyarakat.

Masyarakat Desa Kaliboto Kidul tidak dapat dipisahkan dari ajaran-ajaran Islam kehidupan sehari-hari. Islam dan Madura seperti dua hal yang tidak dapat dipisahkan dan berhubungan erat satu sama lain. Perilaku masyarakat Desa Kaliboto Kidul sangat kental dengan-ajaran-ajaran Islam. ${ }^{17}$ Status seseorang bagi masyarakat Madura dapat dilihat dari kadar ke-Islaman yang melekat pada dirinya. Simbol agama Islam tertinggi yang dipakai sebagai patokan adalah Ulama dan haji. ${ }^{18}$

Berdasarkan hasil wawancara dengan KH. Abdul Aziz yang dikumpulkan peneliti, menyatakan:

Saonggunah para ulama' tak ndik wewenang nannganin masalah carok jia, engkok dinnak gun ngopenin santreh se ngajih. Engkok ye tak bisa nyoro ben alarang. Mon masalah alanglang, para ulama ye bisah bein alanglang, jek jiah disamping tak olleh derih agemah ye tak olle derih hukum pemerenta. Ben, ajiah benni tanggungennah ulama' moloh,tapeh tanggung jawab seluruh lapisan masarakat kanggui ngelakonin apah-apah se elarang bik apah-apah se eperenta gusteh alloh.

Sesungguhnya Ulama tidak punya wewenang untuk melerai kedua pelaku yang akan melakukan carok. Saya disini hanya sekedar pendidik para santri yang mau belajar saja. Berbicara tentang carok, para ulama hanya bisa memberiahu dan mengarahkan, bahwacarok selain dilarang oleh agama juga oleh pemerintah (hukum positif). Seharusnya bukan hanya seorang Ulama saja yang bisa memberi nasehat kepada pelaku carok akan tetapi masyarakat juga memberikan kontribusi yang signifikan. ${ }^{19}$

\footnotetext{
${ }^{16}$ Moh. E. Hasim, Kamus Istilah Islam, Bandung: Pustaka Pelajar, 1987, h. 164

17 Rifai, Manusia..., h. 347.

18 Taufiqurrahman, Islam..., h. 7.

19 Wawancara dengan KH. Abdul Aziz di kediaman Desa Kaliboto Kidul 04 Januari 2019.
} 
Disamping penjelasan yang disampaikan oleh KH. Abdul Aziz kemudian juga mencari data kepada salah satu dan Ustd. Muhammad Yusuf Ya'kub, berikut pemaparan tentang peranananya sebagai salah satu tokoh agama:

Pamorrah ulama jiah asal muassallah derih mapannah tatakramah se elakonin. Saenggennah nglaeragi karakter ben daya tarik masyarakat molaen derih sesemak sampek se jeu. Deddih monla e tegguk betek ngak jiah insyaallah debunnah ekedingagi masyarakat.

Kharisma Ulama yang memperoleh dukungan dan kedudukan ditengah masyarakat terletak pada kemantapan sikap dan kualitas yang dimilikinya, sehingga melahirkan etika kepribadian penuh daya tarik, proses ini bermula dari kalangan terdekat kemudian mampu menjalar ke tempat berjauhan, Ulama dalam hal ini dikategorikan sebagai elit agama, sehingga jika hal demikian sudah mendarah daging maka segala fatwa yang disampaikan akan diimplementasikan oleh masyarakat. ${ }^{20}$

Dengan demikian, fatwa atau nasehat para ulama menjadi kata kunci bagi permasalahan carok. Dengan mempertimbangkan hal-hal yang menjadi panutan bagi seluruh lapisan masayarakat.

b. Metode Hukum Dalam Menyikapi Budaya Carok Pada dasarnya, Islam telah melarang kaum muslim melakukanpembunuhan tanpa ada alasan yang dibenarkan oleh syariat. Keharaman pembunuhan telah ditetapkan berdasarkan Al-Quran dan Sunnah. Allah SWT berfirman yang artinya: Hai orang-orang yang beriman, diwajibkan atas kamu qishaash berkenaan dengan orang-orang yang dibunuh; orang merdeka dengan orang merdeka, hamba dengan hamba, dan wanita dengan wanita. Maka Barangsiapa yang mendapat suatu pema'afan dari saudaranya, hendaklah (yang mema'afkan) mengikuti dengan cara yang baik, dan hendaklah (yang diberi ma'af) membayar (diat) kepada yang memberi ma'af dengan cara yang baik (pula). yang demikian itu adalah suatu keringanan dari Tuhan kamu dan suatu rahmat. Barangsiapa yang melampaui batas sesudah itu, Maka baginya siksa yang sangat pedih. ${ }^{21}$ Dan

${ }^{20}$ Wawancara dengan Ustd. Muhammad Yusuf Ya'kub di kediaman Desa Kaliboto Kidul. 04 Januari 2019.

${ }^{21}$ Qishaash ialah mengambil pembalasan yang sama. qishaash itu tidak dilakukan, bila yang membunuh mendapat kema'afan dari ahli waris yang terbunuh Yaitu dengan membayar diat (ganti rugi) yang wajar. pembayaran diat diminta dengan baik, umpamanya dengan tidak mendesak yang membunuh, dan yang membunuh hendaklah membayarnya dengan baik, umpamanya tidak menangguh-nangguhkannya. bila ahli waris si korban sesudah Tuhan menjelaskan hukum-hukum ini, membunuh yang bukan si pembunuh, atau membunuh si pembunuh setelah menerima diat, Maka terhadapnya di dunia diambil qishaash dan di akhirat Dia mendapat siksa yang pedih. 
dalam qishaash itu ada (jaminan kelangsungan) hidup bagimu, Hai orang-orang yang berakal, supaya kamu bertakwa. ${ }^{22}$

\section{Metode yang DigunakanUlama dalam upaya Resolusi KonflikCarok di Desa Kaliboto Kidul}

Metode hukum yang digunakan para Ulama di Desa Kaliboto Kidul merujuk pada maqashid syariah, yang mana di dalam maqashid syariahterdapat beberapa tujuan hukum Islam, diantaranya:

a. Hifdz Ad-Din (Memelihara Agama)

Pemeliharaan agama merupakan tujuan pertama hukum Islam.Karena agama merupakan pedoman hidup manusia, dan di dalamAgama Islam selain komponen-komponen akidah yang merupakansikap hidup seorang muslim, terdapat juga syariat yang merupakansikap hidup seorang muslim baik dalam berhubungan denganTuhannya maupun dalam berhubungan dengan manusia lain danbenda dalam masyarakat. Karena itulah maka hukum Islam wajibmelindungi agama yang dianut oleh seseorang dan menjaminkemerdekaan setiap orang untuk beribadah menurut keyakinannya.Beragama merupakan kekhususan bagi manusia, merupakankebutuhan utama yang harus dipenuhi karena agamalah yang dapatmenyentuh nurani manusia.

b. Hifdz An-Nafs (Memelihara Jiwa)

Untuk tujuan ini, Islam melarang pembunuhan dan pelaku pembunuhan diancam dengan hukuman Qishas. Diharapkan agarorang sebelum melakukan pembunuhan, berpikir panjang karenaapabila orang yang dibunuh itu mati, maka pembunuh juga akan matiatau jika orang yang dibunuh itu tidak mati tetap hanya cedera, makapelakunya juga akan cedera.

C. Hifdz Al"Aql (Memelihara Akal)

Manusia adalah makhluk Allah SWT, ada dua hal yang membedakan manusia dengan makhluk lain. Pertama, Allah SWTtelah menjadikan manusia dalam bentuk yang paling baik,dibandingkan dengan bentuk makhluk-makhluk

\footnotetext{
${ }^{22}$ Alquran surat Al-Baqarah: 178-179.
} 
lain dari berbagaimakhluk lain. Akan tetapi bentuk yang baik itu tidak ada gunanya,kalau tidak ada hal yang kedua, yaitu akal.

d. Hifdz An-Nasb (Memelihara Keturunan)

Perlindungan Islam terhadap keturunan adalah dengan mensyariatkannya pernikahan dan mengharamkan zina, menetapkansiapa-siapa yang tidak boleh dikawini, bagaimana cara-caraperkawinan itu dilakukan dan syarat-syarat apa yang harus dipenuhi,sehingga perkawinan itu dianggap sah dan pencampuran antara duamanusia yang berlainan jenis itu tidak dianggap sah dan menjadiketurunan sah dari ayahnya.

e. Hifdz Al-Maal (Memelihara Harta)

Islam meyakini bahwa semua harta di dunia ini adalah milik Allah SWT, manusia hanya berhak untuk memanfaatkannya saja.Meskipun demikian Islam juga mengakui hak pribadi seseorang. Olehkarena manusia itu manusia sangat tamak kepada harta benda,sehingga mau mengusahakannya dengan jalan apapun, maka Islammengatur supaya jangan sampai terjadi bentrokan antara satu samalain. Untuk itu Islam mensyariatkan peraturan-peraturan mengenaimuamalah seperti jual beli, sewa-menyewa, gadai menggadai, dansebagainya, serta melarang penipuan, riba dan mewajibkan kepadaorang yang merusak barang orang lain untuk membayarnya, hartayang dirusak oleh anak-anak yang di bawah tanggungannya, bahkanyang dirusak oleh binatang peliharaannya sekalipun.

\section{KESIMPULAN}

a. Dalam prakteknya budaya carok yang terjadi di Desa Kaliboto Kidul tergantungkapan harga diri seseorang merasa dilecehkan. Hal tersebut bisa secaraspontan atau direncanakan sebelumnya, sehingga disaat harga diriseseorang dilecehkan maka pada saat itu pula carok dilaksanakan.Mengenai siapa yang melakukan carok, semua data empiris yang ditelitioleh penulis secara jelas menunjuk semua orang yang merasa harga dirinyatelah dilecehkan sehingga merekalah yang selalu melakukannya.

b. Dalam hal ini ada beberapa peran ulama dalam mengatasi pelaku carokselama ini: 
1) Biasanya para pelaku carok, sebelum melakukan caroknyabis/sowan(bertamu) untuk meminta restu dan nasehat kepada ulama. Disini peranulama untuk memberi nasehat jika para ulama mengizinkan adanyacarok, maka pada saat itu juga carok dilaksanakan.

2) Mencari tahu dari semua akar permasalahan biasanya langsungmendatangi kerumah (yang hendak melakukan carok, pelaku maupunkorban), tetangga sekitar, kerabat dekat pelaku maupun korban bahkandari santri-santri yang tahu tentang persoalan atau masalahpelaku/korban.

3) Memberikan nasehat kepada semua warga dan para santri-santrinya diselaselawaktu, biasanya dilakukan ketika ada acara, tahlilan, istigosah,pengajian dan sidang jumat agar hal semacam itu (carok) dapat merugikandiri sendiri.

c. Metode yang digunakan para ulama di Desa Kaliboto Kidul merujukpada maqashidsyaria'ah yaitu mashlahah dan kemudaratannya.Kesimpulannya bahwa semua konsep maqashid syari'ah adalah tentagkebaikan dan kesejahteraan umat manusia baik di dunia (denganmu'amalah) maupun di akhirat (dengan aqidah dan ibadah). Sedangkancara untuk tercapai kemaslahatan tersebut manusia harus memenuhikebutuhan dharuriat dan menyempurnakan kebutuhan hajiyat dantahsiniat atau kamaliat.

\section{REFERENSI}

Ali, Zainuddin, Hukum Pidana Islam, Jakarta: Sinar Grafika Offest, 2009.

Astuti, Andri, Hukum Adat: Modul 1, Surakarta: UNS Press, 1995.

Azwar, Syaifuddin, Metode Penelitian, Yogyakarta: Pustaka Pelajar, 2005.

Bakri, H.M.K Hukum Pidana Dalam Islam, Jakarta, Ramadhani Sala, 1958.

Bruinessen, Martin, NU Tradisi Relasi-Relasi Kuasa Pencarian Wacana Baru, Yogyakarta: LKiS, 1994.

Dhofier, Zamakhsyari, Studi Tentang Pandangan Hidup Kyai, Jakarta: LP3ES, 1994.

Djazuli, Akhmad, Fiqih Jinayah Upaya Menanggulangi Kejahatan Dalam Islam, Jakarta: Raja Grafindo Persada, 1997.

El-Bantany, Rian Hidayat, Kamus Pengetahuan Islam Lengkap, Bandung: Mutiara Allamah Utama, 2014. 
Erie Hariyanto, Carok VS Hukum Pidana Indonesia (ProsesTransformasi Budaya Madura Kedalam Sistem Hukum Indonesia), dalam Karsa, VOL. XII, edisi 2 Oktober, 2007.

Hakim, Rahmat, Fiqih Jinayah Hukum Pidana Islam, cet 2, Bandung: Pustaka Setia, 2000.

Haliman, Hukum Pidana Islam Menurut Ajaran Aswaja, Jakarta: Bulan Bintang, 1967.

Hasim, E.M, Kamus Istilah Islam, Bandung: Pustaka Pelajar, 1987.

Hastijanti, Retno, Pengaruh Ritual Carok Terhadap Pemukiman TradisionalMadura, dalam Dimensi Tekhnik Arsitektur, Vol. 33 No. 1, Juli 2005.

Hefner,Robert W. Islam Pasar Keadilan: Artikulasi Lokal, Kapitalisme dan Demokrasi. Yogyakarta: LKiS. 2000.

Ibnu Hajar, Al-Hafidz, Terjemahan Bulughul Maram, Surabaya: Mutiara Ilmu, 1995.

Kuntowijoyo, Perubahan Sosial Dalam Masyarakat Agraris Madura, Jogjakarta: Mata Bangsa, 2002.

Mien A Rifai, Manusia Madura Pembawaan Perilaku Etos Kerja Penampilandan Pandangan Hidupnya Seperti Dicitrakan Peribahasanya, Yogyakarta: Pilar Media, 2007.

Moeljatno, KUHP Kitab Undang-Undang Hukum Pidana, Jakarta: Bumi Aksara, 2009.

Moloeng, J. Lexy. Metode Penelitian Kualitatif, Bandung: Remaja Rosda Karya, 2002.

Mubarok, Jain, Enceng Arif Faizal, Kaidah Fiqih Jinayah, Jakarta: IKPI, 2004.

Muchtarom, Zaini. Islam di Jawa dalam Perspektif Santri dan Abangan. Jakarta: Salemba Diniyah, 2002.

Munajat, Makhrus, Dekonstruksi Hukum Pidana Islam, Jogjakarta: Logung Pustaka, 2004.

Muslich, A. Wardi, Pengantar dan Asas Hukum Pidana Islam Fiqih Jinayah, Jakarta: Sinar Grafika, 2004.

Notosusanto, Nugroho, Masalah Penelitian Sejarah, Jakarta: Yayasan Idayu, 1978.

Partanto, A. Pius, dan Al-Barry, M. Dahlan, Kamus Ilmiah Populer, Surabaya: Arkola, 1994.

Qoyyim, Ibnu, Kyai Jawa dan Peranannya di Masa Kolonial, Jakarta: Gema Insani Press, 1997.

Rahman, Abdur, Tindak Pidana Dalam Syariat Islam, Jakarta: Putra Melton, 1992.

Ridwan, Limitasi Hukum Pidana Islam, Semarang: Walisongo Press, 2008.

Rifa’i, Terjamah Khulashah Kifayatul Akhyar, Semarang: Toha Putra Semarang, 1978.

Subahri, Bambang. Pesan simbolik tradisi sandingan pada masyarakat pandalungandi desa Jenggrong kecamatan Ranuyoso kabupaten Lumajang. Dakwatuna Jurnal Vol. 4 No. 2 Agustus 2018.

Subaharianto, Andang, Tantangan Industrialisasi Madura : Membentur Kultur Menjunjung Leluhur, Malang: Bayumedia Publishing, 2004.

Sugiyono, Memahami Penelitian Kualitatif, Bandung: Alfabeta, 2005. 
Sutarto,Ayu. "Sekilas tentang Masyarakat Pandalungan," Makalah disampaikan pada acara pembekalan Jelajah Budaya 2006 yang diselenggarakan oleh Balai Kajian Sejarah dan Nilai Tradisional Yogyakarta, tanggal 7-10 Agustus 2006.

Wiyata, Latif, Carok Konflik Kekerasan dan Harga Diri Orang Madura, Yogyakarta: LKiS, 2002. 